\title{
Influence of Adiponectin and Leptin on the Kinetics of Human Pulp Cells
}

\author{
Isao Tamura1 ${ }^{*}$, Katsura Ueda1, Yoshifumi Matsuda1, Aiko Kamada², Yoshihiro Yoshikawa², \\ Eisuke Domae², Takashi Ikeo², Shunji Kumabe ${ }^{1}$
}

${ }^{1}$ Department of Oral Anatomy, School of Dentistry, Osaka Dental University 8-1 Kuzuhahanazono-cho, Hirakata-shi, Osaka, Japan ${ }^{2}$ Department of Biochemistry, School of Dentistry, Osaka Dental University 8-1 Kuzuhahanazono-cho, Hirakata-shi, Osaka, Japan Email: ^tamura@cc.osaka-dent.ac.jp

How to cite this paper: Tamura, I., Ueda K., Matsuda, Y., Kamada, A., Yoshikawa, Y., Domae, E., Ikeo, T. and Kumabe, S. (2020) Influence of Adiponectin and Leptin on the Kinetics of Human Pulp Cells. Open Journal of Stomatology, 10, 360-371. https://doi.org/10.4236/ojst.2020.1012033

Received: November 19, 2020 Accepted: December 14, 2020 Published: December 17, 2020

Copyright () 2020 by author(s) and Scientific Research Publishing Inc. This work is licensed under the Creative Commons Attribution International License (CC BY 4.0).

http://creativecommons.org/licenses/by/4.0/

\begin{abstract}
Adipocytokines, such as adiponectin and leptin, are expressed by adipocytes and are known as anti-metabolic syndrome factors. They are also thought to mediate calcification in mineralized tissue. We investigated the effects of adiponectin and leptin on the kinetics of human pulp cells using ELISA and western blot. After gaining informed consent, we obtained human pulp cells from three patients. After cultivation in Dulbecco's Modified Eagle Medium (DMEM) without serum, cells from the 4th to 6th passages were incubated with various concentrations of adiponectin $(1,10$, or $100 \mathrm{ng} / \mathrm{mL})$ in DMEM or leptin $(0.1,1$, or $10 \mathrm{ng} / \mathrm{mL})$ in DMEM for $24 \mathrm{~h}$. We confirmed that human pulp cells expressed adiponectin receptor 1 and leptin receptor. Although the proliferation index of these cells as measured by 5-bromo-2'-deoxyuridine (BrdU) incorporation increased in the presence of adiponectin in a dose-dependent manner, pulp cells stimulated with leptin showed no significant changes in BrdU incorporation. Alkaline phosphatase activity showed no significant changes after stimulation with either adipocytokine. Adiponectin induced expression of BMP-2 and osteopontin more strongly than did leptin. In particular, expression of BMP-2 increased in the presence of adiponectin in a dose-dependent manner. In contrast, the expression of dentin sialoprotein increased after stimulation with leptin. The expression of Runx2 was not observed from the cultured pulp cells stimulated with both molecules. These results indicate that adiponectin and leptin contribute to growth and differentiation of human pulp cells and may consequently affect the formation of secondary dentin or reparative dentin in the dentin-pulp complex.
\end{abstract}

\section{Keywords}

Dental Pulp Cells, Adiponectin, Leptin, Bone Morphogenetic Protein-2, Dentin Sialoprotein, Osteopontin, ECM Formation 


\section{Introduction}

The dentin-pulp complex promotes changes like the formation of secondary dentin and the accumulation of collagen fibrils after tooth formation. Additionally, sclerotic dentin in the dentin tubule, reparative dentin at the surface of secondary dentin, and denticles in pulp tissues are formed in reaction to various stimuli. It is thought that the cells that form hard tissue localize in the pulp tissue even after the completion of tooth formation. In fact, human pulp cells show high alkaline phosphatase activity in vitro [1] and in the cell-rich zones of pulp tissues [2] and pulp tissues contain stem cells [3] [4]. Odontoblasts show osteoblast-like characteristics by expressing runt-related transcription factor 2 (Runx2) [5] and bone morphogenetic protein-2 (BMP-2) [6], and they secrete osteopontin (OPN), osteocalcin, and dentin sialophosphoprotein [7]. It is thought that odontoblasts promote mineralized tissue formation by the deposition of dentin matrix components, the same as in the initial mineralized region between predentin and the odontoblastic zone.

Adiponectin and leptin are mainly secreted by adipocytes, are localized in fatty tissues and serum, and function as mediators of sclerosis and diabetes by accelerating fatty acid oxidation in fat tissue, regulating glucose concentrations in serum [8], and negatively regulating body weight by stimulating the satiety center and sympathetic nervous system [9]. It has been previously shown that osteoblasts also express adiponectin, which along with its receptor (AdpR) induces the expression of RANKL and promotes the differentiation of osteoclasts [10], while knockdown of AdpR1 in osteoblasts reduces this differentiation and calcification [11]. Leptin receptor (LeptinR) also localizes to the membranes of osteoblasts, and leptin reduces the expression of RANKL in osteoblasts directly or through the sympathetic nervous system, resulting in the activation of osteoclasts [12]. However, there is no information on functions of adiponectin and leptin in human pulp cells.

To investigate the effects of adiponectin and leptin on the kinetics of human pulp cells, in this study we examined the expressions of Runx2, BMP-2, dentin sialoprotein (DSP), and OPN using ELISA and western blot.

\section{Materials and Methods}

\subsection{Pulp Cell Cultures}

All experiments were approved by the Ethics Committee of Osaka Dental University on March 6th in 2005 (No. 050351, principal investigator is Takashi Ikeo). Primary pulp cultures were obtained from three patients with informed consent as previously described [13]. The tissues were initially cultured in Dulbecco's Modified Eagle Medium (DMEM, Nacalai Tesque, Kyoto, Japan) supplemented with $2 \mathrm{mM}$ L-glutamine, $100 \mu \mathrm{g} / \mathrm{mL}$ streptomycin, $100 \mathrm{IU} / \mathrm{mL}$ penicillin, and 10\% FCS (ICN Biomedicals, Aurora, OH, USA) in a humidified atmosphere containing $5 \% \mathrm{CO}_{2}$ in air at $37^{\circ} \mathrm{C}$. Then three of the pulp cell cultures between the 4th and 6th passage were cultured in DMEM without FCS for two 
days, and subsequently were cultured in DMEM supplemented with 1, 10, or 100 $\mathrm{ng} / \mathrm{mL}$ recombinant human adiponectin (BioVender, Brno, Czech Republic) or $0.1,1$, or $10 \mathrm{ng} / \mathrm{mL}$ recombinant human leptin (MoBiTec, Göttingen, Germany), $100 \mu \mathrm{g} / \mathrm{mL}$ streptomycin and $100 \mathrm{IU} / \mathrm{mL}$ penicillin for $45 \mathrm{~min}$. Controls were treated identically, except that neither protein was added.

\subsection{Western blot for AdpR and LeptinR}

Pulp cells were cultivated in $25-\mathrm{cm}^{2}$ tissue culture flasks and then lysed. The cell lysates were solubilized in SDS-PAGE sample buffer, and protein concentrations were determined using the bicinchoninic acid method [14]. Equal amounts of protein samples were fractionated and then transferred electrophoretically onto PVDF membranes [15]. After blocking with $1 \%$ bovine serum albumin (BSA) at $4^{\circ} \mathrm{C}$ overnight and incubation with anti-AdpR 1 antibody or anti-LeptinR1 antibody as described in Table 1 at $4^{\circ} \mathrm{C}$ overnight, the proteins were labeled by the indirect method of streptavidin-biotin [16]. Protein bands were then visualized by subsequent exposure of the membranes on X-ray film, with the molecular size of proteins, specificity of antibodies, and expression of each protein confirmed.

\subsection{5-Bromo 2'-Deoxyuridine (BrdU) Incorporation}

The proliferation of cultured pulp cells was evaluated by measuring BrdU incorporation (Oncogene Research Products, Cambridge, MA, USA), which was measured by indirect enzyme-linked immunosorbent assay (ELISA). The cultures were seeded at a density of 3000 cells/well in 96-well plates. After incubating with adiponectin or leptin at each concentration in DMEM and $10 \mu \mathrm{M}$ BrdU for 45 $\mathrm{min}, \mathrm{BrdU}$ incorporation was measured using peroxidase-conjugated anti-BrdU antibody according to the manufacturer's instructions (Oncogene Research Products). The means and standard errors for measured value were calculated.

\subsection{Analysis of ALP Activity}

Cells in 96-well plates were washed with PBS including 0.2\% NP-40 and $1 \mathrm{mM}$ $\mathrm{MgCl}_{2}$. After washing, ALP activity was determined by the $p$-nitro phenylphosphate method [17]. The means and standard errors for measured value were calculated.

Table 1. List of antibodies.

\begin{tabular}{cccc}
\hline & Manufacturer & Clone & Dilution* $^{*}$ \\
\hline AdpRl & Alpha Diagnostic & anti-AdipoRl & $1 \mu \mathrm{g} / \mathrm{mL}: 40$ \\
LeptinR & Sigma & L9411 & $100 \mu \mathrm{g} / \mathrm{mL}: 1000$ \\
Runx2 & Santa Cruz Biotec. & C-19 & $1 \mathrm{~mL}: 50$ \\
BMP-2 & R\&D Systems & 100221 & $100 \mu \mathrm{g} / \mathrm{mL}: 1000$ \\
DSP & Santa Cruz Biotec. & C-20 & $1 \mathrm{~mL}: 100$ \\
OPN & Chemicon Inter. & anti-P10451 & $1 \mathrm{~mL}: 500$ \\
\hline
\end{tabular}

*All antibodies were diluted by PBS supplemented with 1\% BSA. 


\subsection{Western Blot Analyses of Proteins Related to Pulp Cell Kinetics}

The expressions of proteins in pulp cells or tissues were examined by western blot as described above. Culture supernatants were concentrated by VIVAPORE (VIVASCIENCE, Lincoln, UK) and mixed with cells, following dissolution in SDS-PAGE sample buffer. After transfer onto PVDF membranes and blocking with $1 \%$ BSA, each first antibody as described in Table 1 was reacted at $4^{\circ} \mathrm{C}$ overnight, and the proteins were labeled by the indirect method of streptavidin-biotin [16].

\section{Results}

\subsection{Expression of AdpR1 and LeptinR}

We performed western blot to confirm the expressions of AdpR1 and LeptinR (Figure 1). These analyses showed that the exposure of pulp cells to DMEM supplemented with adipocytokines had different kinetics. In pulp cells, the expression of AdpR1 was gradually increased in the presence of adiponectin in a dose-dependent manner. LeptinR was expressed at a low concentration of leptin, but the expression of LeptinR was diffuse and showed no significant dosedependent changes. We could not detect AdpR2 from pulp cells stimulated with adiponectin (data not shown).

\subsection{BrdU Incorporation}

BrdU incorporation increased in the presence of adiponectin in a dose-dependent manner (Figure 2). Pulp cells stimulated with leptin showed a tendency toward an increase, but there were no significant changes.
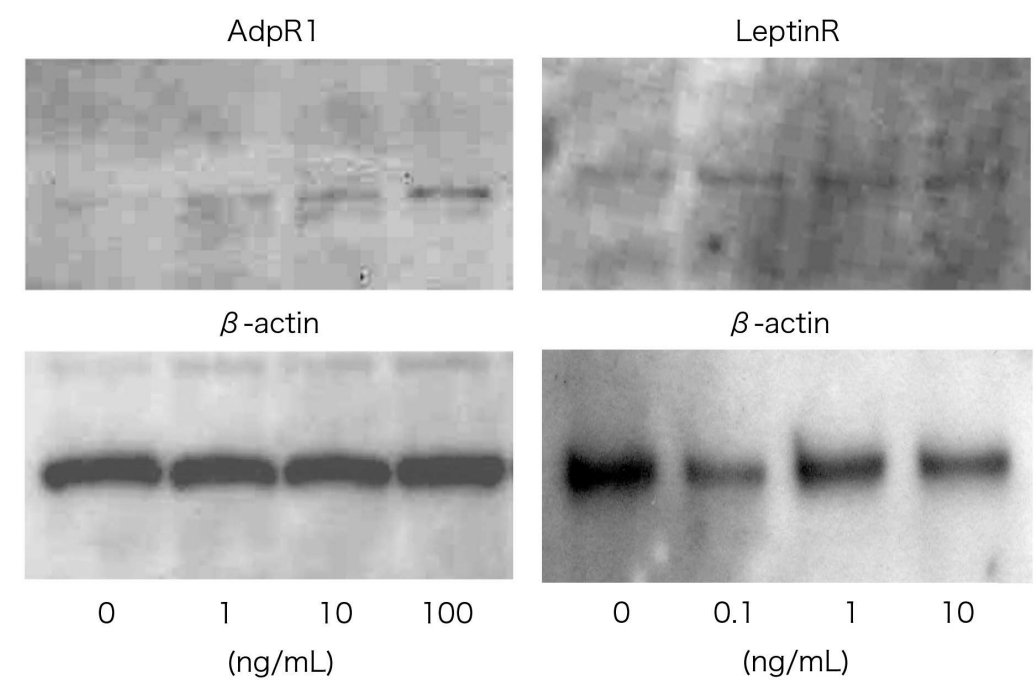

Figure 1. Western blot for adipocytokine receptors. The exposure of pulp cells to DMEM was supplemented with adipocytokines but had different kinetics. In pulp cells, the expression of AdpR1 was gradually increased in the presence of adiponectin in a dose-dependent manner. LeptinR was expressed at a low concentration of leptin. However, the expression of AdpR2 was not detected (data not shown). 

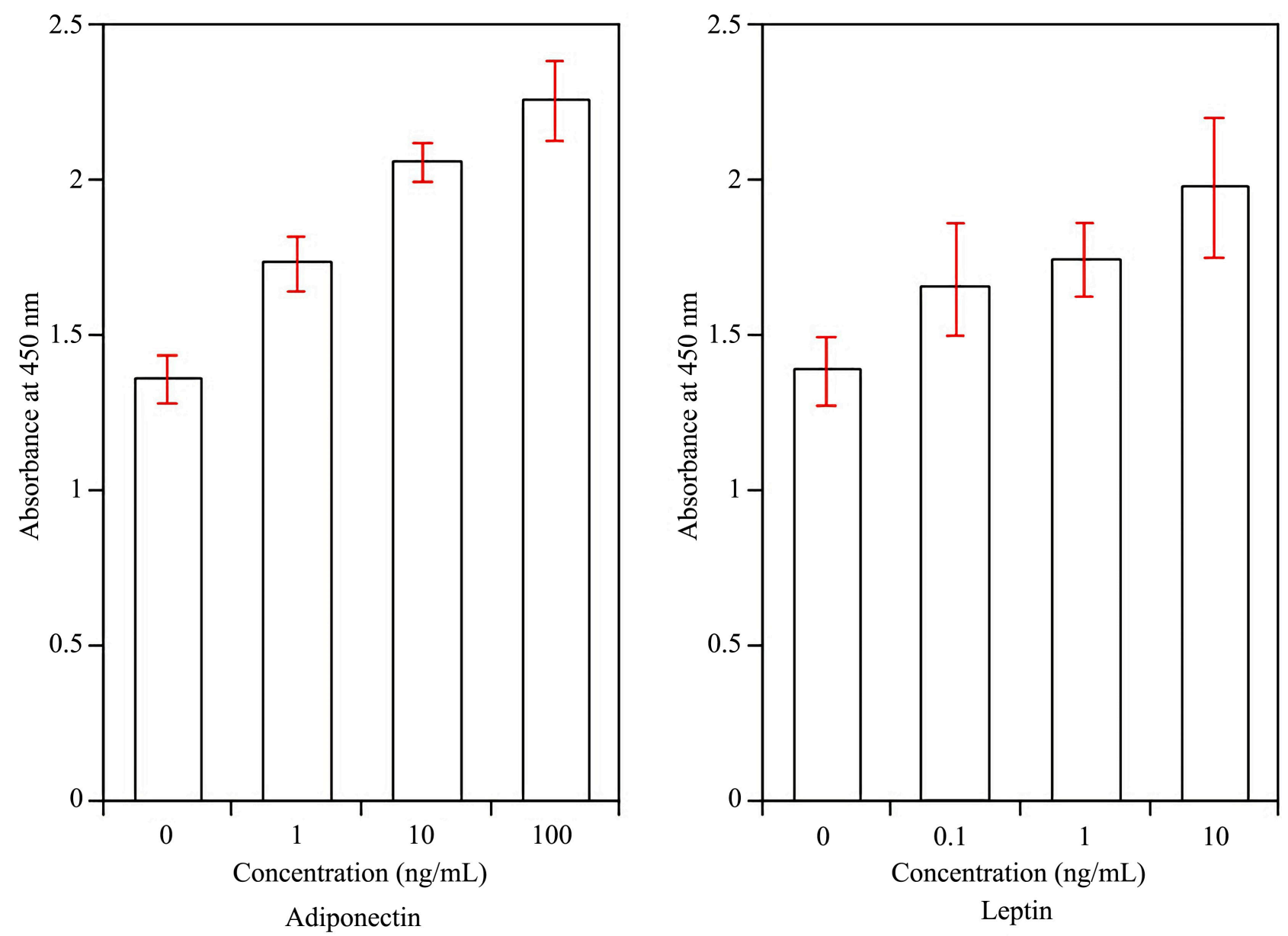

Figure 2. BrdU incorporation of pulp cells cultivated with DMEM supplemented with adiponectin or leptin. BrdU incorporation increased in the presence of adiponectin in a dose-dependent manner, but pulp cells stimulated with leptin showed no significant changes (mean $+\mathrm{SE})$.

\subsection{ALP Activity}

ALP activities were measured in pulp cells cultivated with DMEM supplemented with adiponectin or leptin (Figure 3). ALP activity showed no significant changes after stimulation with either protein in this dose-dependent study.

\subsection{Western Blot Profiles of Runx2}

In this study, the expression of Runx 2 from cultured pulp cells stimulated with adiponectin or leptin was examined by western blot (Figure 4). However, we did not detect the expression of Runx2, even in trace amounts.

\subsection{Western Blot Profiles for the Expressed Proteins from Pulp Cells}

We performed western blot to detect the expressions of kinetics-related proteins from pulp cells (Figure 5). In cultured pulp cells treated with adiponectin, the expression of BMP-2 was gradually increased in a dose-dependent manner. And pulp cells showed that the expressions of DSP and OPN were stimulated by 

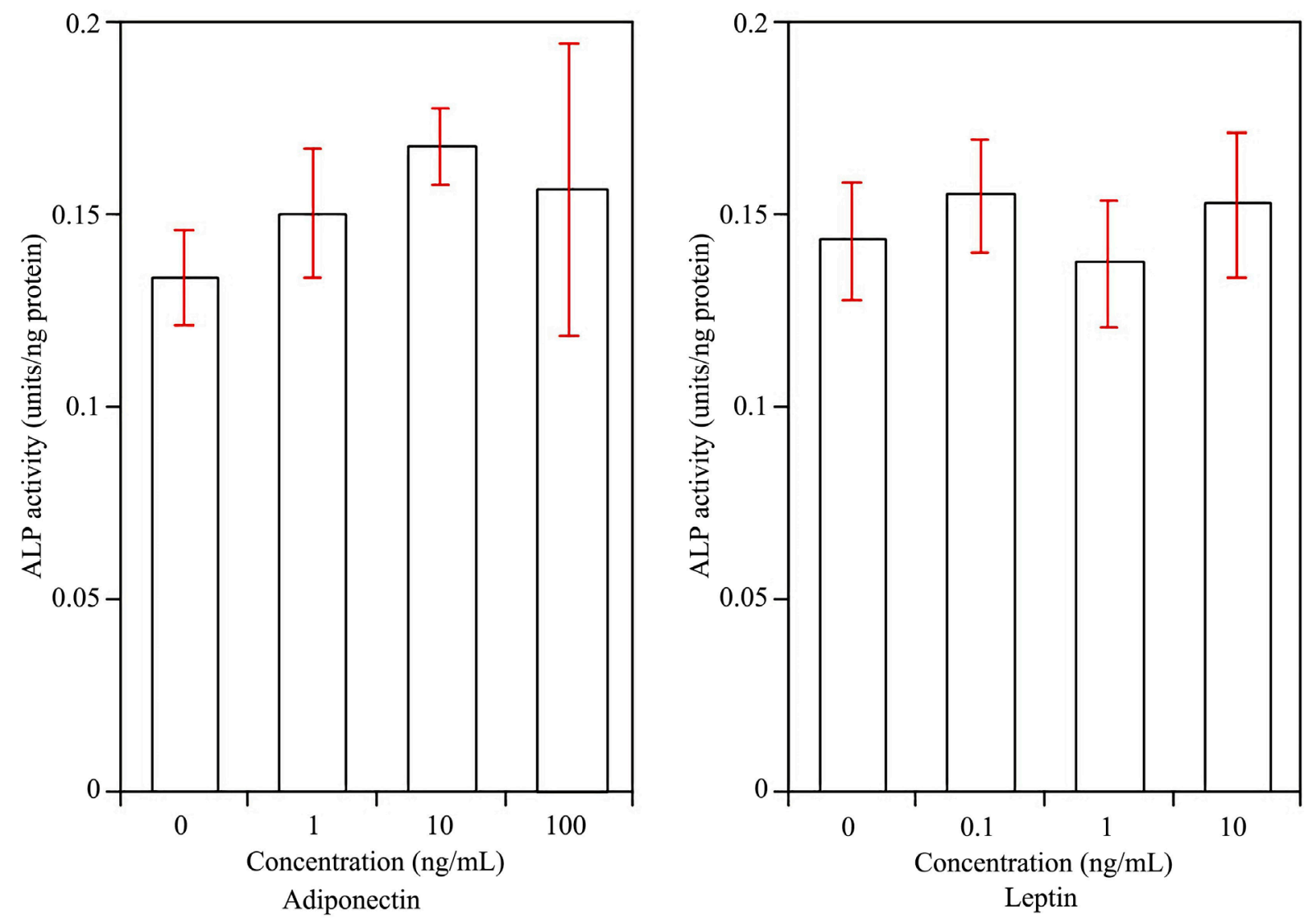

Figure 3. Alkaline phosphatase activity in pulp cells. Alkaline phosphatase activity showed no significant changes after stimulation with either adipokine (mean $+\mathrm{SE})$.

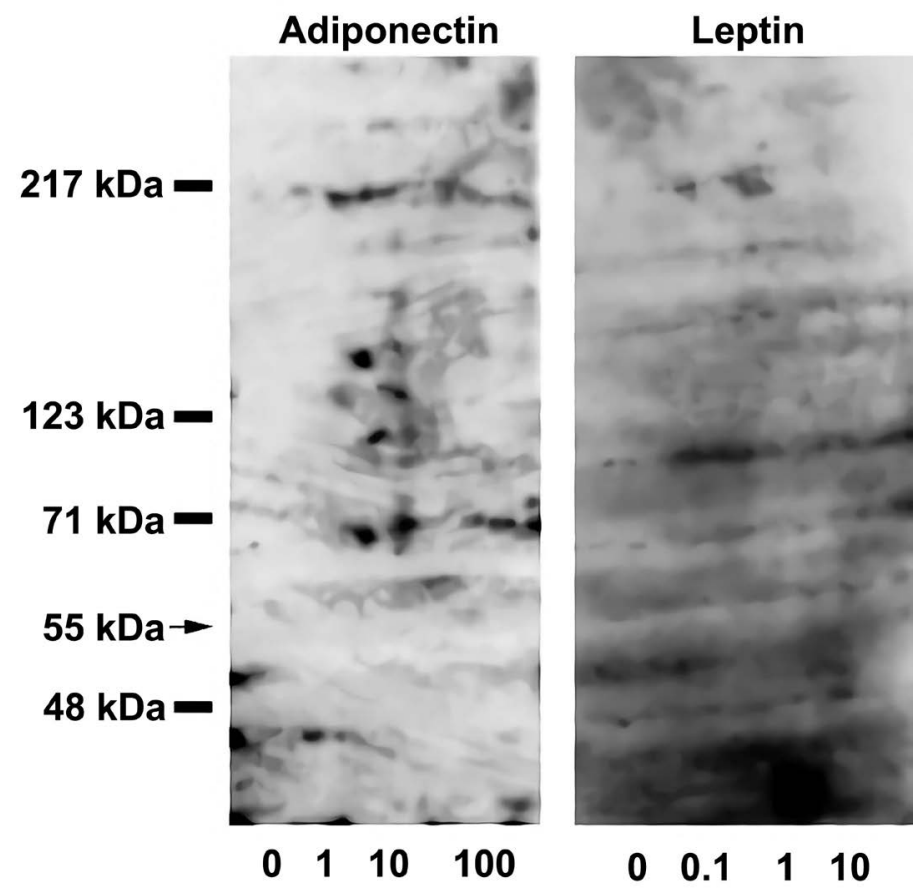

Figure 4. Western blot for Runx2. At the protein level, the expression of Runx2, which appears as a $55 \mathrm{kDa}$ molecule (arrow), was not observed even at trace levels. 
Adiponectin

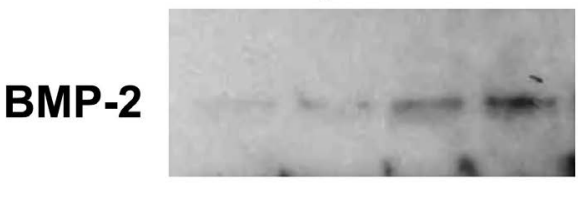

DSP

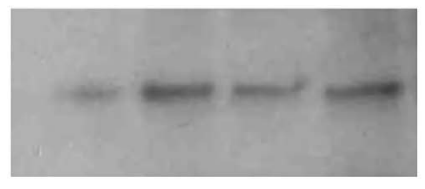

OPN
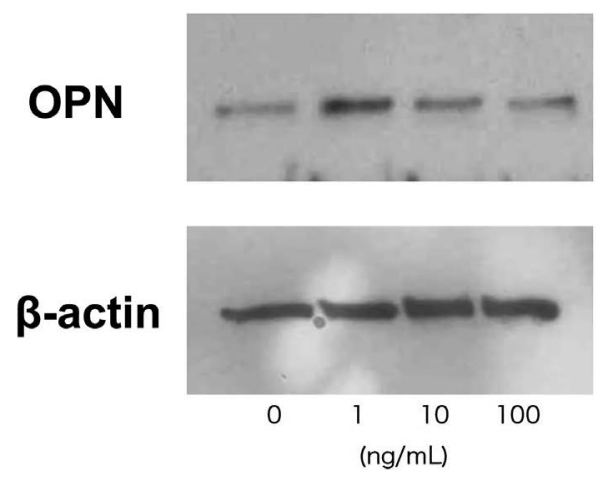
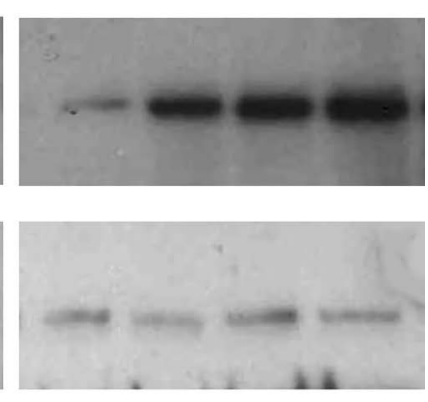

Leptin
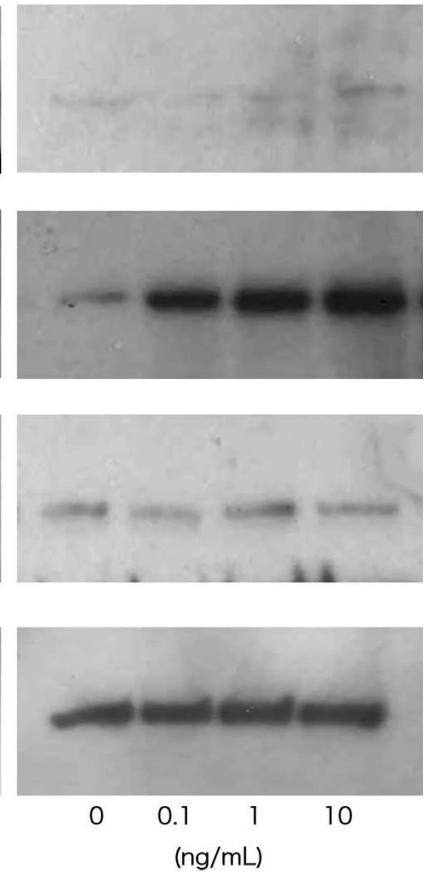

Figure 5. Western blot of dental pulp components. Pulp cells stimulated with adiponectin or leptin gradually expressed BMP-2 in a dose-dependent manner. In pulp cells stimulated with leptin, the expression of DSP was detected clearly. There were no changes in the expression of OPN in pulp cells.

adiponectin, but there was no dose-related stimulation. In cultured pulp cells treated with leptin, the expression of BMP-2 gradually increased. Additionally, the expression of DSP was clearly detected, but there were no changes in the expression of OPN in pulp cells.

\section{Discussion}

Passive calcification and fibril hyperplasia are usually observed among the aging in pulp tissue. However, these changes are found not only in teeth affected by occlusion, mastication, caries, or hypersensitivity, but also in unerupted teeth, and it is inferred that pulp cells are affected under these conditions [18] [19] [20]. Additionally, osteoblasts and osteoclasts are also regulated by adipokines, which promote bone metabolism [10] [12] [21]. Accordingly, as it is thought that adipokines affect the kinetics of pulp cells, we examined the effects of adiponectin and leptin on human pulp cells in this study.

We detected the expressions of AdpR1 and LeptinR, but not AdpR2, by western blot and found that both proteins function as mediators in human pulp cells in this study. Human neonatal dermal fibroblasts [21] and osteoblasts [22] show the expression of AdpR2 mRNA, and we think that pulp cells in this study may express it at trace levels that are undetectable by western blot. Stimulation of the cells with either adiponectin or leptin in a time-dependent manner increased the proliferation index of the cells as measured by BrdU incorporation, and both 
proteins show the same effects on human osteoblast cell proliferation [23] [24]. Conversely, stimulated pulp cells showed no change in ALP activity compared to control cells and showed no expression of Runx2 [20] [25] [26]. ALP activity and the expression of Runx2 were promoted by activated osteoblasts, so isolated pulp cells in this study might not be induced to differentiate into the calcification cells [19].

We also observed the induction of BMP-2 expression in pulp cells treated with each adipokine. It is known that BMP-2 is expressed by pulp cells [27] [28] [29] and fibroblasts from other tissues [30] [31] due to various stimuli, and that BMP-2 induces osteogenesis and the initiation of tissue formation [26] [31] [32]. Additionally, western blot profiles clearly revealed that the expressions of DSP and OPN, which are major dental pulp non-collagenous extracellular matrix proteins, were induced by adiponectin and DSP induced by leptin. DSP in dental pulp, predentin, and dentin is directly synthesized by pulp cells [33] and odontoblasts [34] or localizes there as a result of dentin sialophosphoprotein and DSP-phosphophoryn cleavage [33] [35]. Li et al. [36] demonstrated that the DSP domain induces pulp mesenchymal cell proliferation, angiogenesis, and mineralization in mouse pulp tissues in vivo. It is generally known that OPN includes the RGD sequence and thus participates in cell-matrix adhesion and migration. Moreover, OPN inhibits the growth of apatite crystals by strongly connecting to calcium ions [37]. Interestingly, OPN is expressed by a rat pulp cell line before the onset of mineralization in osteoblastic conditioned medium [25] and accumulates on the outer layer of wounds [38] or predentin during initial wound healing in dental pulp tissue [39]. However, limitation exists in this study. Since first or second passage in culture cells under calcified medium supplemented with b-TCP and ascorbic acid were not used, we might not be able to analyses calcification. It is difficult to analyze earlier passage in culture cells without unsuitable contamination.

In this study, we found that adiponectin and leptin induced the expressions of BMP-2, DSP, and OPN, but not Runx2, in cultured human dental pulp cells. These results indicate that adiponectin and leptin do not participate in mineralization directly, but create an environment for mineralization in the dentin-pulp complex by contributing to the growth and expression of each component in pulp cells. This may consequently affect the formation of secondary dentin or reparative dentin in the dentin-pulp complex.

\section{Acknowledgements}

This study was performed using the Morphological Research Facilities, LowTemperature Facilities, Photograph-Processing Facilities, Analytical Instrument Facilities, and Dental Bioscience Facilities I of the Institute of Dental Research, Osaka Dental University.

\section{Conflicts of Interest}

There are no potential conflicts of interest. 


\section{References}

[1] Shiba, H., Nakanishi, K., Rashid, F., Mizuno, N., Hino, T., Ogawa, T. and Kurihara, H. (2003) Proliferaive Ability and Alkaline Phosphatase Activity with in Vivo Cellular Aging in Human Pulp Cells. Journal of Endodontics, 29, 9-11. https://doi.org/10.1097/00004770-200301000-00003

[2] Aslantas, E.E., Buzoglu, H.D., Karapinar, S.P., Cehreli, Z.C., Muftuoglu, S., Atilla, P. and Aksoy, Y. (2016) Age-Related Changes in the Alkaline Phosphatase Activity of Healthy and Inflamed Human Dental Pulp. Journal of Endodontics, 42, 131-134. https://doi.org/10.1016/j.joen.2015.10.003

[3] Hosoya, A., Nakamura, H. (2015) Ability of Stem and Progenitor Cells in the Dental Pulp to Form Hard Tissue. Japanese Dental Science Review, 51, 75-83. https://doi.org/10.1016/j.jdsr.2015.03.002

[4] Hanyu, S., Sakuma, K. and Tanaka, A. (2019) A Study on the Effect of Human Dental Pulp Stem Cell Conditioned Medium on Human Oral Squamous Cell Carcinoma Cell Lines. Journal of Hard Tissue Biology, 28, 281-288.

[5] Chen, S., Rani, S., Wu, Y., Unterbrink, A., Gu, T.T., Gluhak-Heinrich, J., Chuang, H.H. and MacDougall, M. (2005) Differential Regulation of Dentin Sialophosphoprotein Expression by Runx2 during Odontoblast Cytodifferentiation. The Journal of Biological Chemistry, 280, 29717-29727. https://doi.org/10.1074/jbc.M502929200

[6] Yang, W., Harris, M.A., Cui, Y., Mishina, Y. and Gluhak-Heinrich, J. (2012) Bmp2 Is Required for Odontoblast Differentiation and Pulp Vasculogenesis. Journal of Dental Research, 91, 58-64. https://doi.org/10.1177/0022034511424409

[7] Miyazaki, T., Kanatani, N., Rokutanda, S., Yoshida, C., Toyosawa, S., Nakamura, R., Takada, S. and Komori, T. (2008) Inhibition of the Terminal Differentiation of Odontoblasts and Their Transdifferentiation into Osteoblasts in Runx2 Transgenic Mice. Archives of Histology and Cytology, 71, 131-146.

[8] Ikeda, Y., Hama, S., Kajimoto, K., Okuno, T., Tsuchiya, H. and Kogure, K. (2011) Quantitative Comparison of Adipocytokine Gene Expression during Adipocyto Maturation in Non-Obese and Obese Rats. Biological and Pharmaceutical Bulletin, 34, 865-870.

[9] Maffei, M., Halaas, J., Ravussin, E., Pratley, R.E., Lee, G.H., Zhang, Y., Fei, H., Kim, S., Lallone, R., Ranganathan, S., Kern, P.A. and Friedman, J.M. (1995) Leptin Levels in Human and Rodent: Measurement of Plasma Leptin and $o b$ RNA in Obese and Weight-Reduced Subjects. Nature Medicine, 1, 1155-1161.

https://doi.org/10.1038/nm1195-1155

[10] Luo, X.H., Guo, L.J., Xie, H., Yuan, L.O., Wu, X.P., Zhou, H.D. and Liao, E.Y. (2006) Adiponectin Stimulated RANKL and Inhibits OPG Expression in Human Osteoblasts through the MAPK Signaling Pathway. Journal of Bone and Mineral Research, 21, 1648-1656.

[11] Lin, Y.Y., Chen, C.Y., Chuang, T.Y., Lin, Y., Liu, H.Y., Mersmann, H.J., Wu, S.C. and Ding, S.T. (2014) Adiponectin Receptor 1 Regulates Bone Formation and Osteoblast Differentiation by GSK-3 $\beta / \beta$-Catenin Signaling in Mice. Bone, 64, 147-154. https://doi.org/10.1016/j.bone.2014.03.051

[12] Turner, R.T., Kalra, S.P., Wong, C.P., Phibrick, K.A., Lindenmaier, L.B., Boghssian, S. and Iwaniec, U.T. (2013) Peripheral Leptin Regulates Bone Formatioin. Journal of Bone and Mineral Research, 28, 22-34.

[13] Tamura, I., Sakaki, T., Nishikawa, T., Tnaka, Y., Amakata, S., Kakudo, K., Tanaka, 
A. and Ikeo, T. (2004) Expression of Early Growth Response-1 and -2 in Human Periodontal Ligament Fobroblasts. Journal of Osaka Dental University, 38, 31-36.

[14] Smith, P.K., Krohn, R.I., Hermanson, G.T., Mallia, A.K., Gartner, F.H., Provenzano, M.D., Fujimoto, E.K., Goeke, N.M., Olson, B.J. and Klenk, D.C. (1985) Measurement of Protein Using Bicinchoninic Acid. Analytical Biochemistry, 150, 76-85. https://doi.org/10.1016/0003-2697(85)90442-7

[15] Towbin, H., Staehelin, T. and Gordon, J. (1979) Electrophoretic Transfer of Proteins from Polyacrylamide Gels to Nitrocellulose Sheets: Procedure and Some Applications. Proceedings of the National Academy of Sciences of the United States of America, 76, 4350-4354. https://doi.org/10.1073/pnas.76.9.4350

[16] Shi, Z.R., Itzkowitz, S.H. and Kim, Y.S. (1988) A Comparison of Three Immunoperoxidase Techniques for Antigen Detection in Colorectal Carcinoma tissues. Journal of Histochemistry \& Cytochemistry, 36, 317-322.

https://doi.org/10.1177/36.3.3278057

[17] Yamamoto, M., Takahashi, Y. and Tabata, Y. (2003) Controlled Release by Biodegradable Hydrogels Enhances the Ectopic Bone Formation of Bone Morphogenetic Protein. Biomaterials, 24, 4375-4383. https://doi.org/10.1016/S0142-9612(03)00337-5

[18] Kim, S.G., Solomon, C., Zheng, Y., Suzuki, T., Mo, C., Jiang, N., Cho, S., Zhou, J. and Mao, J.J. (2012) Effects of Growth Factors on Dental Stem/Progenitor Cells. Dental Clinics of North America, 56, 563-575. https://doi.org/10.1016/j.cden.2012.05.001

[19] Ueda, K., Matsuda, Y., Ueno, K., Uemura, M., Yoshikawa, Y., Domae, E., Kamada, A., Toda, I., Takemura, A., Kumabe, S., Ikeo, T. and Tamura, I. (2019) Effects of IGF-I on Kinetics of Early Growth Response-1 in Human Dental Pulpal Cells. Journal of Osaka Dental University, 53, 25-30.

[20] Tian, S., Wang, J., Dong, F., Du, A., Li, W.J., Song, P. and Liu, Y.P. (2019) Concentrated Growth Factor Promotes Dental Pulp Cells Proliferation and Mineralization and Facilitates Recovery of Dental Pulp Tissue. Medical Science Monitor, 25, 1001610028. https://doi.org/10.12659/MSM.919316

[21] Liu, Y., Song, C.Y., Wu, S.S., Liang, Q.H., Yuan, L.Q., Liao, E.Y. (2013) Novel Adipokines and Bone Metabolism. International Journal of Endocrinology, 2013, Article ID: 895045.https://doi.org/10.1155/2013/895045

[22] Ezue, T. and Amano, S. (2007) Adiponectin and Leptin Up-Regulate Extracellilar Matrix Production by Dermal Fibroblasts. BioFactors, 31, 229-236. https://doi.org/10.1002/biof.5520310310

[23] Luo, X.H., Guo, L.J., Yuan, L.Q., Xie, H., Zhou, H.D., Wu, X.P. and Liao, E.Y. (2005) Adiponectin Stimulates Human Osteoblasts Proliferation and Differentiation via the MAPK Signaling Pathway. Experimental Cell Research, 309, 99-109. https://doi.org/10.1016/j.yexcr.2005.05.021

[24] Gordeladze, J.O., Drevon, C.A., Syversen, U. and Reseland, J.E. (2002) Leptin Stimulates Human Osteoblastic Cell Proliferation, de Novo Collagen Synthesis, and Mineralization: Impact on Differentiation Markers, Apoptosis, and Osteoclastic Signaling. Journal of Cellular Biochemistry, 85, 825-836. https://doi.org/10.1002/jcb.10156

[25] Ueno, A., Kitase, Y., Moriyama, K. and Inoue, H. (2001) MC3T3-E1-Conditioned Medium-Induced Mineralization by Clonal Rat Dental Pulp Cells. Matrix Biology, 20, 347-355. https://doi.org/10.1016/S0945-053X(01)00141-X

[26] Ogasawara, T., Kawaguchi, H., Jinno, S., Hoshi, K., Itaka, K., Takato, T., Nakamura, 
K. and Okayama, H. (2004) Bone Morphogenetic Protein 2-Induced Osteoblast Differentiation Requires Smad-Mediated Down-Regulation of Cdk6. Molecular and Cellular Biology, 24, 6560-6568. https://doi.org/10.1128/MCB.24.15.6560-6568.2004

[27] Gu, K., Smoke, R.H. and Rutherford, R.B. (1997) Expression of Genes for One Morphogenetic Proteins and Receptors in Human Dental Pulp. Archives of Oral Biology, 41, 919-923. https://doi.org/10.1016/S0003-9969(96)00052-0

[28] Rashid, F., Shiba, H., Mizuno, N., Mouri, Y., Fujita, T., Shinohara, H., Ogawa, T., Kawaguchi, H. and Kurihara, H. (2003) The Effect of Extracellular Calcium Ion on Gene Expression of Bone-Related Proteins in Human Pulp Cells. Journal of Endodontics, 29, 104-107. https://doi.org/10.1097/00004770-200302000-00004

[29] Jittapiromsak, N., Jettanacheawchankit, S., Lardungdee, P., Sangvanich, P. and Thunyakitpisal, P.D. (2007) Effect of Acemannan on BMP-2 Expression in Primary Pulpal Fibroblasts and Periodontal Fibroblasts, in Vitro Study. Journal of Oral Tissue Engineering, 4, 149-154.

[30] Sakamoto, A., Oda, Y., Iwamoto, Y. and Tsuneyoshi, M. (2007) Frequent Immunoexpression of TGF- $\beta 1$, FGF-2 and BMP-2 in Fibroblast-Like Cells in Osteofibrous Dysplasia. Oncology Reports, 17, 531-535.

https://doi.org/10.3892/or.17.3.531

[31] Schwarting, T., Schenk, D., Frink, M., Benölken, M., Steindor, F., Oswald, M., Ruchholtz, S. and Lechler, P. (2016) Stimulation with Bone Morphogenetic Protein-2 (BMP-2) Enhances Bone-Tendon Integration in Vitro. Connective Tissue Research, 57, 99-112. https://doi.org/10.3109/03008207.2015.1087516

[32] Go, Y.Y., Mun, J.Y., Chae, S.W., Kim, S.H., Song, H. and Song, J.J. (2018) Engineering Functional BMP-2 Expressing Teratoma-Derived Fibroblasts for Enhancing Osteogenesis. Scientific Reports, 8, Article No. 14581.

https://doi.org/10.1038/s41598-018-32946-6

[33] Yamakoshi, Y. and Simmer, J.P. (2018) Structural Features, Processing Mechanism and Gene Splice Variants of Dentin Sialophosphoprotein. Japanese Dental Science Review, 54, 183-196. https://doi.org/10.1016/j.jdsr.2018.03.006

[34] Narayanan, K., Srinivas, R., Ramachandran, A., Hao, J., Quinn, B. and George, A. (2001) Differentiation of Embryonic Mesenchymal Cells to Odontoblast-Like Cells by Overexpression of Dentin Matrix Protein 1. Proceedings of the National Academy of Sciences of the United States of America, 98, 4516-4521.

https://doi.org/10.1073/pnas.081075198

[35] Ritchie, H. (2018) The Functional Significance of Dentin Sialoprotein-Phosphophoryn and Dentin Sialoprotein. International Journal of Oral Science, 10, Article No. 31. https://doi.org/10.1038/s41368-018-0035-9

[36] Li, W., Chen, L., Chen, Z., Wu, L., Feng, J.S., Wang, F., Shoff, L., Li, X., Donly, K.J., MacDougall, M. and Chen, S. (2017) Dentin Sialoprotein Facilitates Dental Mesenchymal Cell Differentiation and Dentin Formation. Scientific Reports, 7, Article No. 300. https://doi.org/10.1038/s41598-017-00339-w

[37] Icer, M.A. and Gezmen-Karadag, M. (2018) The Multiple Functions and Mechanisms of Osteopontin. Clinical Biochemistry, 59, 17-24. https://doi.org/10.1016/j.clinbiochem.2018.07.003

[38] Kuratate, M., Yoshiba, K., Shigetani, Y., Yoshiba, N., Oshima, H. and Okiji, T. (2008) Immunohistochemical Analysis of Nestin, Osteopontin, and Proliferating Cells in the Reparative Process of Exposed Dental pulp Capped with Mineral Trioxide Aggregate. Journal of Endodontics, 34, 970-974.

https://doi.org/10.1016/j.joen.2008.03.021 
[39] Saito, K., Nakatomi, M., Ida-Yonemochi, H. and Ohshima, H. (2016) Osteopontin is Essential for Type I Collagen Secretion in Reparative Dentin. Journal of Dental Research, 95, 1034-1041. https://doi.org/10.1177/0022034516645333 